\title{
Photoelastic Analysis of Two Different Cementless Femoral Stems for Total Hip Arthroplasty in a Canine Model
}

\author{
Fernando Y. K. Kawamoto ${ }^{1}$ Bruno W. Minto ${ }^{1}$ Lucia M. I. Diogo ${ }^{1}$ Luis G. de Faria ${ }^{1 \odot}$ \\ Antonio C. Shimano ${ }^{2}$ Ana P. Macedo ${ }^{2}$ José A. A. Camassa ${ }^{3}$ Luis G. G. G. Dias ${ }^{1}$
}

${ }^{1}$ Department of Veterinary Clinic and Surgery, Faculty of Agrarian and Veterinary Sciences, São Paulo State University, Jaboticabal, São Paulo, Brazil

2 Department of Biomechanics, Ribeirao Preto Medical School, Ribeirão Preto, Sao Paulo, Brazil

${ }^{3}$ Department of Veterinary Science, University of Trás-os-Montes and Alto Douro, Vila Real, Portugal
Address for correspondence Bruno W. Minto, DVM, PhD, Department of Veterinary Clinic and Surgery, Faculty of Agrarian and Veterinary Sciences, São Paulo State University, Via de Acesso Prof. Paulo Donato Castellane, s/n, Jaboticabal, SP, 14884-900, Brazil (e-mail: brunowminto@gmail.com).

VCOT Open 2019;2:e36-e42.

\begin{abstract}
Keywords

- orthopaedic implants

- prostheses

- biomechanics

Objectives The aim of this article was to analyse and compare internal stress generated at different points of a femoral photoelastic model after insertion and axial load application using two different cementless femoral stems for total hip arthroplasty in dogs: a collared stem combined with limited textured surface and absence of grooves and a collarless stem with fully textured surface and grooves.

Methods Ten femoral photoelastic models, divided into two groups, were created using two different designs of cementless femoral stems. The models were submitted to axial loading on the femoral head in a universal test machine. The internal stress $(\mathrm{kPa})$ around the femoral stems was evaluated at seven predetermined points using a transmission polariscope.

Results The internal stress at the femoral calcar was larger in the models with collared stem combined with limited textured surface and absence of grooves $(p<0.05)$. No differences were identified between the groups in the other points $(p>0.05)$, corresponding to the tip of the stems and proximal lateral region of the femur.

Conclusions The collar of femoral stem combined with the absence of grooves and more limited textured surface increase the axial load transmission to the femoral calcar, and in vivo, it may act to reduce complications, such as subsidence and stress shielding. However, other biomechanical tests and clinical evaluations must be performed to determine other important aspects for the implantation of these prostheses.
\end{abstract}

\section{Introduction}

A total hip arthroplasty is the only procedure capable of eliminating pain and recovering limb function with close-to-

(1D) Luis Guilherme de Faria's ORCID is https://orcid.org/0000-0002-
9563-1870.

received

October 13, 2018

DOI https://doi.org/

accepted after revision

April 10, 2019
$10.1055 / \mathrm{s}-0039-1691792$

ISSN 2625-2325. normal articular motion in patients with diseases involving the coxofemoral joint. ${ }^{1-6}$ The complications associated with the use of cementless prostheses include luxation, femoral fissures and fractures, ${ }^{6}$ subsidence and adaptive remodeling. ${ }^{7,8}$

Different femoral stem types will result in specific bone reactions, which will depend mainly on their rigidity,
License terms

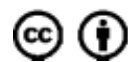

(c) 2019 Georg Thieme Verlag KG

Stuttgart · New York 
geometry and surface coating. Inadequate stress distribution and intensity along the osseous tissue adjacent to the femoral stem of the hip prosthesis may predispose to stress shielding, fractures and subsidence. ${ }^{7}$ The implant design may directly influence the type and frequency of complications. ${ }^{8}$ Several femoral stem designs have therefore been developed and investigated to prevent or reduce these complications. ${ }^{9}$

Photoelasticity is an experimental method to evaluate stress and deformations in structures with complex geometries. $^{10}$ The photoelastic analysis method is capable of demonstrating the distribution of stress visually and quantitatively, mimicking applied loads to obtain internal stresses in vitro that are similar to those that occur in vivo. ${ }^{11}$ The results can be extrapolated to serve as a parameter for the distribution of stress generated at the bone-implant interface for the selected prosthesis model. ${ }^{12}$ Studies using photoelasticity as a test for coxofemoral prostheses in dogs are scarce.

The objective of this study was to use photoelastic analysis to visualize and measure the distribution and intensity of internal stress $(\mathrm{kPa})$ for two different femoral stem designs during static axial loading of the system.

\section{Materials and Methods}

The study was performed at the Faculty of Agrarian and Veterinary Sciences, UNESP/Jaboticabal, Brazil and at the Laboratory of Bioengineering, School of Medicine, FMRP/ USP-Ribeirão Preto, Brazil. The methods were approved by the Ethics Committee on the Use of Animals of the Faculty of Agrarian and Veterinary Sciences, UNESP/Jaboticabal, Brazil (protocol no 16938/16).

\section{Orthopaedic Implants}

The implants were constructed using surgical stainless steel, covered with a $\mathrm{Cr}$ - Co - Mo alloy (ASTM F75) and sprayed with titanium plasma. Femoral stem ' 1 ' was sprayed with titanium only in its proximal portion, while femoral stem ' 2 ' had a fully textured surface. The main difference between the two implants was the presence of a collar near the femoral neck of stem ' 1 ' and a bulging (protuberance) and oblique grooves in the proximal region of stem '2' (-Fig. 1).

The stems were measured and selected through a radiographic template so that the mean canal fill was $>85 \%$. Due to the structural difference between the stems, different sizes were needed for an adequate accommodation in the same bone model. A $17-\mathrm{mm} \emptyset,+0$ (neutral) femoral head and 28-mm acetabular cup were selected.

\section{Femur Model}

Tomographic and radiographic images of the right femur of an adult dog cadaver of approximately $25 \mathrm{~kg}$-obtained after arthroplasty excision of the femoral head and neck-were used to obtain the contour of the femur. Based on these images, a plane acrylic femur was produced, similar to the drawing, with $14 \mathrm{~mm}$ in width. A structure in acrylic for the correct positioning and support of the femoral stem was also constructed, and an acrylic box with $65 \mathrm{~mm}$ in width,

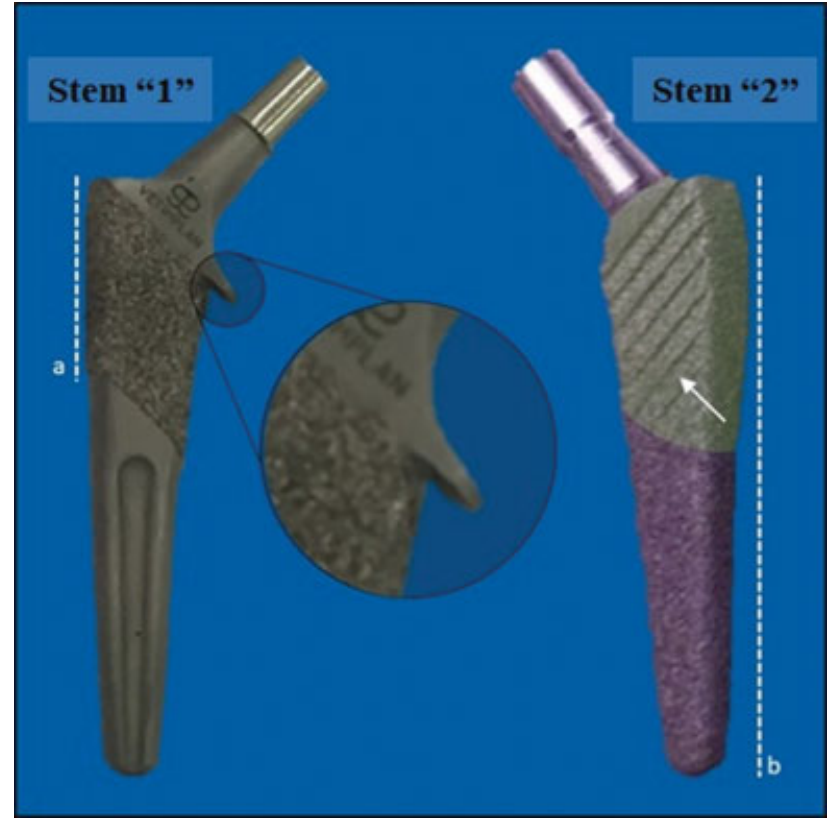

Fig. 1 Photograph showing femoral stems ' 1 ' and '2.' Note the structural differences in design. The dashed line shows that femoral stem ' 1 ' (A) had a titanium coating only in its proximal portion, while femoral stem '2' (B) had a fully textured surface. Note that femoral stem ' 1 ' had an extension of the femoral neck (collar) (on magnification). Femoral stem ' 2 ' had an enlargement with oblique grooves (white arrow) in its proximal region (highlighted).

$251 \mathrm{~mm}$ in length and $29 \mathrm{~mm}$ in height. Based on the acrylic femur model, two negative moulds (one for each stem design) in blue silicone rubber were obtained to mould the femurs out of photoelastic resin with the femoral stems positioned in their medullary canals.

While obtaining the moulds, the acrylic femur was positioned in the centre of the acrylic box, which was completely filled with $275 \mathrm{~mL}$ of blue silicone and 5\% of catalyst. The acrylic femur was removed after solidification of the silicone. The portion of the proximal area of the femur filled with blue silicone (corresponding area to the femoral head and neck) was removed with a scalpel blade for the positioning of the acrylic piece and the femoral stem. Defects were then filled again. There were two moulds for the proper positioning of the prosthesis because of the difference in design between the stems. The moulds had the same dimensions, with a small difference in the location of the acrylic piece that stabilized the stem until the solidification of the acrylic resin.

\section{Building the Models Out of Photoelastic Resin}

The stems were centred within the medullary cavity of the silicone mould and stabilized using the acrylic piece. Once they were positioned, the photoelastic resin type Araldite GY279 and curing reagent Aradur 296311 were prepared at a ratio of $2: 1$. The resin was then placed inside a vacuum chamber for 20 minutes to eliminate bubbles. Immediately after that, the resin was poured into the mould (-Fig. 2). After polymerization of the resin (72 hours), the final model was obtained. 


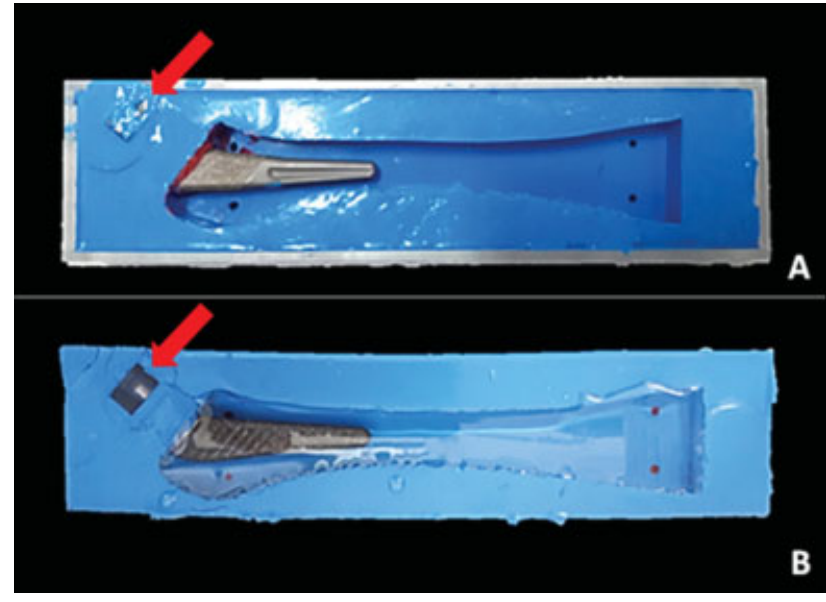

Fig. 2 Photograph showing (A) femoral stem ' 1 ' adequately positioned in the silicone mould using an acrylic piece (red arrow). (B) femoral stem ' 2 ' positioned with the help of an acrylic piece (red arrow) after filling the silicone mould with photoelastic resin.

\section{Experimental Groups}

For the analyses in this study, two silicone moulds were made for the moulding of 10 photoelastic resin models. Two equal moulds, but with a different position of the acrylic piece keeping the stem in its central position, had to be developed because of the different stem designs. These models were divided into two experimental groups, called group 1-five photoelastic resin femur models with femoral stem ' 1 ' and group 2-five photoelastic resin femur models with femoral stem ' 2 '.

\section{Methods for Photoelastic Analysis}

A transmission polariscope model FL200 was used. The device belonged to the Laboratory of Bioengineering at FMRP/USP-Ribeirão Preto/Brazil, where the analyses were performed. The femur was positioned in the polariscope so that the femoral diaphysis was parallel to the direction of the load. ${ }^{4}$ In addition, the acetabular cup (size $28 \mathrm{~mm}$ ) was adapted so that the photoelastic model would remain in a vertical position while the axial loading was applied to the femoral head of the models. Polymethylmethacrylate was placed on the convex surface of the acetabular implant to this end, with a fine-thread hexagon head screw inserted at its vertex.

The static axial loading tests of the photoelastic resin femoral stem assembly were performed with the force being applied vertically to compress the head of the prosthesis. A pilot study was performed to determine the resistance limit of the photoelastic material using an EMIC (Equipment and Systems Testing LTDA) universal testing machine (maximum capacity of 10,000 kgf) to standardize the force being applied. The load cell used had $490.5 \mathrm{~N}$ (50 kgf) ( - Fig. 3). All the tests were performed with the samples under a controlled temperature with a mean of $23^{\circ} \mathrm{C}$.

\section{Analysis Procedure}

The samples were first submitted to a process to eliminate residual stress, that is, any pre-existent stresses prior to the

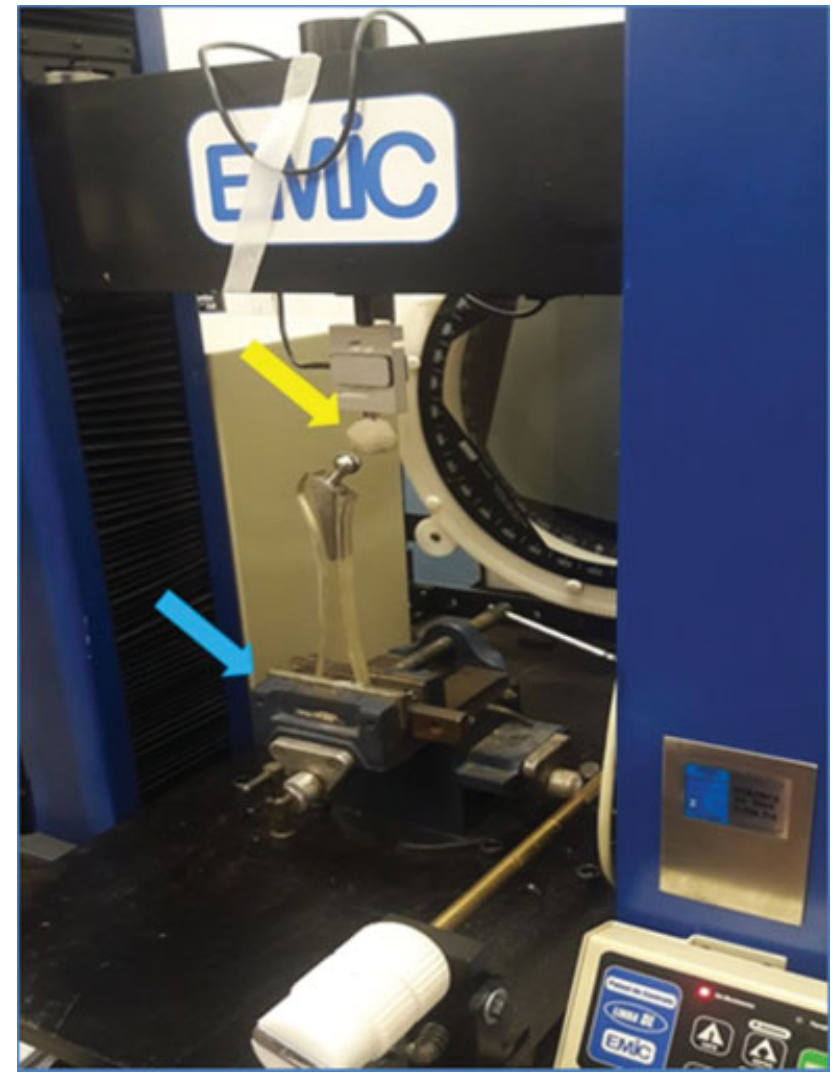

Fig. 3 Photograph demonstrating the photoelastic model, adequately positioned and stabilized by a device at its base similar to a vise (blue arrow), and acetabular dome $(28 \mathrm{~mm})$ adapted to and fixed to the load cell (yellow arrow).

application of the load and analysis were removed. This was done by placing the samples in a laboratory heating oven at $50^{\circ} \mathrm{C}$ for 10 minutes and then leaving them in a room at $23^{\circ} \mathrm{C}$ for 20 minutes to allow the models to cool down. Afterwards, they were once again placed in a laboratory heating oven at $50^{\circ} \mathrm{C}$ for 5 minutes and again cooled as previously described for 10 minutes.

They were then properly positioned and an axial compression force of $100 \mathrm{~N}$ was applied to the femoral head of the stem, generating sufficient internal stress in the photoelastic femur for analysis. The points of analysis were the same in groups 1 and 2 (-Fig. 4) and they were marked at the same distance from the specific parts of the two stems when the proportions of the prosthesis design were taken into consideration. Points 1 and 2 were located in the proximal lateral region at the protuberance in stem ' 2 '; their objective was to evaluate and compare the internal stress brought on by this difference in the design. Points 3,4 and 5 were distributed around the distal extremity of the femoral stem, which is an area more predisposed to subsidence. Finally, points 6 and 7 were placed in the region of the femoral calcar in the same location of the bone, which is the support region for the collar present in stem ' 1 '; a region where stress shielding and fractures may occur. - Figure 5 shows the distribution of internal stresses along the stem analysed using a polariscope. 


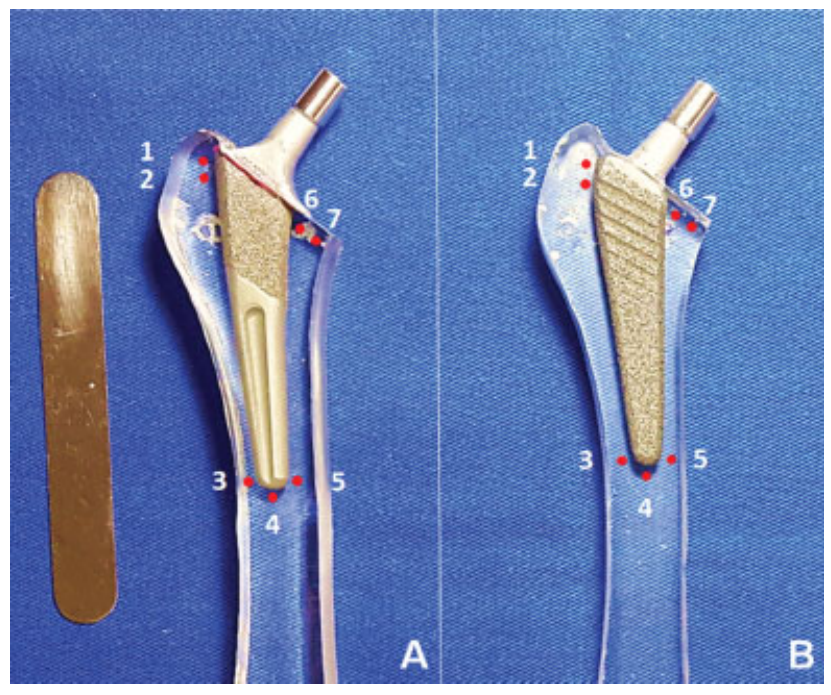

Fig. 4 Photograph showing the seven predetermined locations around the femoral stem ' 1 ' (A) and femoral stem '2' (B) used for photoelastic analysis. Note the presence of a magnifier with a length of $10 \mathrm{~cm}$.

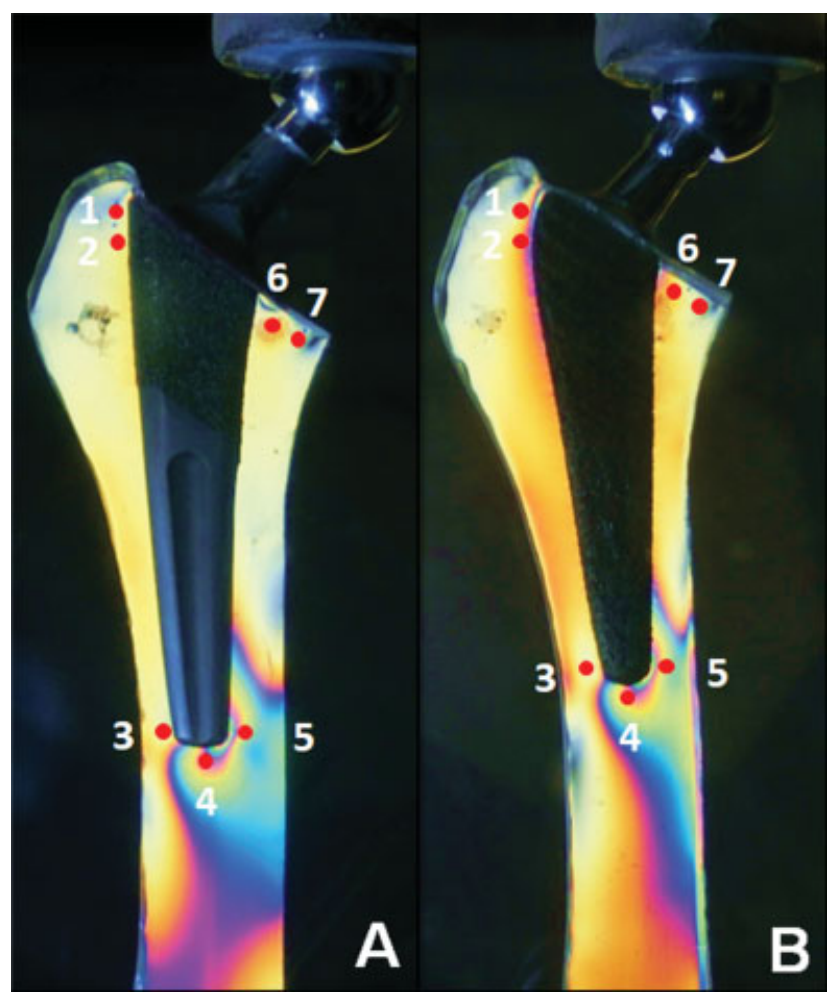

Fig. 5 Photograph demonstrating the distribution of internal stress around the femoral stem ' 1 ' (A) and ' 2 ' (B) in a photoelastic femur model. Note the seven predetermined points for analysis.

The fringe order $(N)$ and shear stress were calculated for each point to obtain the quantitative data. The fringe order $(N)$ was measured from point to point using the Tardy compensation method. ${ }^{13}$ The maximum shear stress $(\tau)$ in each point was obtained using the stress-optic law ${ }^{14}$ based on the thickness of the model $(b)$, with the measurement of the proximal region being standardized using a caliper, and knowing the optical constant for the photoelastic resin $(\mathrm{k} \sigma=3.57)^{15}$ in Brewsters and the values for the fringe order $(N)$. The variable resulting from the photoelastic analysis during static axial loading in groups 1 and 2 is the internal stress $(\mathrm{kPa})$ caused by the implant in the photoelastic model, calculated using the following formula:

$$
\tau=\frac{\boldsymbol{k}_{\sigma} \times N}{2 \times b}
$$

\author{
$b$-thickness of the model \\ $\tau$-maximum shear stress \\ $N$-fringe order

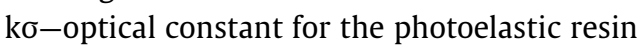

\section{Statistical Analysis}

The normality of the data was tested. Points 1 through 5 had a normal distribution and were analysed using Student's $t$ test. Points 6 and 7 did not have a normal distribution and were compared using the Mann-Whitney U test. A significance level of $5 \%(p=0.05)$ was set for all tests. The statistical analysis was done using the SPSS software, version 23 .

\section{Results}

The photoelastic models of each group were evaluated independently after application of the load (100N) at the femoral head of the stem and the resulting internal stress. The authors would like to highlight that the pattern of the fringes may vary according to the width of the photoelastic model.

- Table 1 shows the quantified values (in $\mathrm{kPa}$ ) for internal stress transmitted to the areas adjacent to the implants, for each point under study.

After the comparative test, it was observed that group 1 had significantly higher values $(p<0.05)$ for the resultant variable at points 6 and 7 . No significant differences were identified for the other points $(p>0.05)$.

Table 1 Internal stress ( $\mathrm{kPa}$ ) analysed via photoelasticity during axial loading tests in stems with collar and stems without collar

\begin{tabular}{|l|l|l|}
\hline Point & Stems with collar & Stems without collar \\
\hline 1 & $47.46 \pm 65.52$ & $45.28 \pm 45.80$ \\
\hline 2 & $66.41 \pm 67.70$ & $78.01 \pm 28.17$ \\
\hline 3 & $90.29 \pm 60.62$ & $55.53 \pm 13.09$ \\
\hline 4 & $224.88 \pm 29.58$ & $257.50 \pm 65.63$ \\
\hline 5 & $189.55 \pm 82.66$ & $197.69 \pm 48.88$ \\
\hline 6 & $94.26 \pm 61.74^{*}$ & $64.35 \pm 28.53$ \\
\hline 7 & $34.46 \pm 24.60^{*}$ & $21.50 \pm 13.50$ \\
\hline
\end{tabular}

The corresponding values are expressed as median $( \pm)$ interquartile interval.

*Indicate significant differences $(p<0.05)$. 


\section{Discussion}

Despite the variety of systems used and more than 30 years of studies on the use of total cementless hip prostheses, the complication rates still range from 5 to $20 \%{ }^{16}$ In vitro studies involving different models and designs are therefore highly relevant to try and find improvements and modifications that can reduce complication rates. ${ }^{9}$

Cementless collared stems were developed with the goal of reducing such complications as subsidence, periprosthetic fractures and stress shielding. ${ }^{17,18}$ However, there is still controversy regarding its advantages and disadvantages. ${ }^{17,19,20}$

Femoral stems with diaphyseal anchoring can reduce bone density at the metaphyseal region of the femur, a phenomenon known as stress shielding. ${ }^{7,9}$ Whether stress shielding is a direct cause of specific clinical complications has not been confirmed, however. ${ }^{4,7,8,21-24}$ From another perspective, stress shielding is not progressive and therefore does not represent a risk factor for fractures, aseptic loosening and other complications in dogs. ${ }^{25}$

The differences in the observed internal stress concentrations when comparing the two femoral stem designs were located at points 6 and 7 , at the region corresponding to the femoral calcar. In vivo, the femoral calcar would receive more internal stress during load application resulting from weightbearing in stem 1 (collared stem with absence of grooves and a less textured surface). The assumption that could be made from this result is that there would be a biomechanical and clinical contribution in vivo in reducing the incidence of subsidence and stress shielding. ${ }^{17}$ In the literature, these findings are controversial. In a biomechanical study, Kim and colleagues ${ }^{8}$ compared stress distribution between an intact femur and the Helica prosthesis. The design of this implant allows it to be screwed into the lateral cortex of the proximal femur using a helical thread, preserving the femoral neck and therefore maintaining the anatomy and biomechanical properties close to normal. In that study, a reduction in stress at the medial, lateral and cranial cortical surfaces of the proximal diaphysis was observed, which is indicative of stress shielding in a clinical setting.

Using biomechanics and histology, Manley and colleagues ${ }^{26}$ compared the influence of a collared and collarless femoral stem in dogs, immediately and 4 months after placement. They observed a significant increase in cortical porosity at the proximal femur, although there was no difference in stress concentrations on the cortical surfaces. In the present study, internal stress concentrations were evaluated intracortically, which permitted the authors to observe a difference. The photoelastic analysis demonstrated that the internal stress in the calcar of group 1 was higher than in group 2. However, the internal stress present in the intact photoelastic femur model has to be quantified and compared with the data obtained after the placement of a stem 1 .

In a randomized prospective clinical trial to determine the effect of a collar on a cementless femoral stem, Meding and colleagues ${ }^{27}$ compared 103 human patients who received a collared femoral stem and 100 patients who received a collarless femoral stem. They noted that the presence of a collar had no influence on fixation, development of stress shielding or clinical evaluation after 5 years. According to Demey and colleagues, ${ }^{28}$ the presence of a collar in the femoral stem provides additional stability, but not enough for primary stabilization of the system. There is therefore a high risk of subsidence or fracture if secondary osseointegration does not occur. ${ }^{28,29}$

Several stem designs have been developed in human medicine to improve proximal fixation and minimize complications. ${ }^{23,30}$ Other factors have received great attention, especially related to implant rigidity (materials with different elasticity modules), stem length and location of the porous area. Usually, the design aims to allow for a load transfer from the femoral stem to the bone in a way that is as similar as possible to the physiological transfer, minimizing the decrease in mechanical stimulus. ${ }^{31}$ Femoral stems composed of titanium, a flexible metallic substrate that approximates the elastic modulus of cortical bone more closely, enable stresses and strains to be transferred more evenly from the prosthesis to the surrounding proximal femur. These stems therefore minimize the development of disuse atrophy in the cortical bone secondary to mechanical loading when compared with more rigid cobaltchrome stems, ${ }^{32}$ the material used in the stems of this study. Piao and colleagues ${ }^{33}$ performed biomechanical testing on two femoral stem designs and found that the titanium implant generated less stress shielding than the cobalt molybdenum chromium implant due to the lower elastic modulus.

Several studies with animal models have shown that stems with less stiffness are associated with less cortical bone loss, but that they may compromise osteointegration by increasing tension at the bone-implant interface. ${ }^{31}$ The femoral stem used in this study was composed of chromium cobalt molybdenum, but the effects related to the material used were not observed, since other materials were not evaluated.

The intrinsic material properties in the bone vary according to age and species, making it very difficult to achieve comparable and reliable experimental results. A series of studies have used synthetic materials as a way of replacing cadaver bones in in vitro tests and to predict mechanical characteristics in specific simulations, therefore limiting the experimental error in tests involving prostheses. ${ }^{24}$ Photoelastic materials have different properties than bones but are used in several types of research, mainly in dentistry with the objective of analysing the qualitative responses of the bone and implant interaction after the application of loads. ${ }^{34}$

The use of photoelastic models with the same homogeneous and isotropic characteristics standardizes the specimen, but it has the disadvantage of being unable to mimic the characteristic differences between the cortical and medullary bone. According to Sadowsky and Caputo, ${ }^{35}$ the photoelastic analysis has been successfully used in the study of the interactions between implant characteristics and tissue responses. Although it is not possible to differentiate between the cortical and medullary bone, this method is valid to verify internal stresses generated by different prosthesis models, since even if the magnitude of the internal stress is probably different from the real situation, the locations of the stress concentrations can be pointed out with precision. ${ }^{10,35}$ 
Others limitations of this study involve the use of vastly different stem designs, which made the comparison between the resulting effects and the evidence of specific findings more difficult. Despite the use of a mould to create the models, there may be a discrete difference in the positioning of the stems, which would influence the cortical thickness. In addition, photoelasticity only allows for the measurement of stress at predefined points, while stress is distributed throughout the femur continuously.

In fact, electron beam melting (EBM) technology has been used with good clinical results. This process allows for a porous surface to be printed as an integral part of the stem, instead of making use of a spray or coating. The direct polymerization of the photoelastic material on the implants simulates their complete osseointegration. ${ }^{36}$ We evaluated mainly the implant design in the photoelastic analysis. As such, the distribution and concentration points of the internal stress would not change, even with the use of different technologies to increase osseointegration. Since the amount of external force applied cannot exceed the resistance limit of the photoelastic material, ${ }^{10}$ we do not know how much the use of EBM, plasma spray or sintered bead stems would influence the results, but this may be a limitation to be investigated.

Photoelasticity enabled the authors to observe and measure the magnitude of the internal stress surrounding the implanted femoral stem in the photoelastic model of the femur and it proved therefore to be a viable method to evaluate the coxofemoral prosthesis. Ex vivo studies simulate the situations occurring in vivo in a simplified way. Their results should therefore be interpreted cautiously. The obtained results cannot be generalized for all cementless femoral stems since the individual characteristics of each design influence the results.

\section{Conclusions}

As can be seen, the presence of a collar in the design of stem 1 , combined with a surface with limited texture and no grooves, allowed for a greater load transfer at the area of the femoral calcar. When compared with stem 2 , the internal stress concentration was smaller in the region of the femoral calcar, and there was no significant difference in the other evaluated locations. However, other biomechanical tests and clinical evaluations should be performed to determine and understand other important aspects involved in implanting these prostheses for total hip arthroplasty.

\section{Author Contribution}

Fernando Y. K. Kawamoto and Ana P. Macedo contributed to conception of stuyd, study design, acquisition of data and data analysis and interpretation. Bruno W. Minto, Antonio C. Shimano, and José A. A. Camassa contributed to conception of study, study design, and data analysis and interpretation. Lucia M. I. Diogo contributed to conception of study, study design and acquisition of data and data analysis. Luis G. de Faria and Luis G. G. G. Dias contributed to conception of study and study design. All authors drafted, revised and approved the submitted manuscript.
Conflict of Interest

None declared.

\section{References}

1 Olmstead ML, Hohn RB, Turner TM. A five-year study of 221 total hip replacements in the dog. J Am Vet Med Assoc 1983;183(02): 191-194

2 Kim NS, Alam MR, Jeong IS, Lee JI, Choi IH. Total hip replacement in a dog. J Vet Sci 2005;6(02):169-171

3 Minto BW, Brandão CV, Pereira GJ, et al. Modular hybrid total hip arthroplasty. Experimental study in dogs. Acta Vet Scand 2011; 53:46

4 Dosch M, Hayashi K, Garcia TC, Weeren R, Stover SM. Biomechanical evaluation of the helica femoral implant system using traditional and modified techniques. Vet Surg 2013;42(07):867-876

5 Hariri S, Chun S, Cowan JB, Bragdon C, Malchau H, Rubash HE. Range of motion in a modular femoral stem system with a variety of neck options. J Arthroplasty 2013;28(09):1625-1633

6 Schiller TD. BioMedtrix total hip replacement systems an overview. Vet Clin North Am Small Anim Pract 2017;47(04):899-916

7 Decking R, Puhl W, Simon U, Claes LE. Changes in strain distribution of loaded proximal femora caused by different types of cementless femoral stems. Clin Biomech (Bristol, Avon) 2006;21(05):495-501

8 Kim JY, Hayashi K, Garcia TC, et al. Biomechanical evaluation of screw-in femoral implant in cementless total hip system. Vet Surg 2012;41(01):94-102

9 Schmidutz F, Woiczinski M, Kistler M, Schröder C, Jansson V, Fottner A. Influence of different sizes of composite femora on the biomechanical behavior of cementless hip prosthesis. Clin Biomech (Bristol, Avon) 2017;41:60-65

10 Mahler DB, Peyton FA. Photoelasticity as a research technique for analyzing stresses in dental structures. J Dent Res 1955;34(06): 831-838

11 Gomide HA, Marques PR. Modelos fotoelásticos para o ensino da engenharia. In: XXI Congresso Brasieliro de Ensino de Engenharia 1993, Rio de Janeiro. Anais, 2:623

12 Brodsky JF, Caputo AA, Furstman LL. Root tipping: a photoelastichistopathologic correlation. Am J Orthod 1975;67(01):1-10

13 Oliveira SAG, Gomide HA. Fotoelasticidade plana - material e técnica. In: CBECIMAT 1990, Águas de São Pedro, SP: Anais; 1990;9:608-614

14 Valente MLDC, de Castro DT, Macedo AP, Shimano AC, Dos Reis AC. Comparative analysis of stress in a new proposal of dental implants. Mater Sci Eng C 2017;77:360-365

15 Aguiar FA Jr, Tiossi R, Macedo AP, Mattos MdaG, Ribeiro RF, Rodrigues RC. Photoelastic analysis of stresses transmitted by universal cast to long abutment on implant-supported single restorations under static occlusal loads. J Craniofac Surg 2012; 23(07, Suppl 1):2019-2023

16 Henderson ER, Wills A, Torrington AM, et al. Evaluation of variables influencing success and complication rates in canine total hip replacement: results from the British Veterinary Orthopaedic Association Canine Hip Registry (collation of data: 2010-2012). Vet Rec 2017;181(01):18

17 Jeon I, Bae JY, Park JH, et al. The biomechanical effect of the collar of a femoral stem on total hip arthroplasty. Comput Methods Biomech Biomed Engin 2011;14(01):103-112

18 Forster KE, Wills A, Torrington AM, et al. Complications and owner assessment of canine total hip replacement: a multicenter internet based survey. Vet Surg 2012;41(05):545-550

19 Kwong K. The biomechanical role of the collar of the femoral component of a hip replacement. J Bone Joint Surg Br 1990;72 (04):664-665

20 Meding JB, Ritter MA, Keating EM, Faris PM, Edmondson K. A comparison of collared and collarless femoral components in primary cemented total hip arthroplasty: a randomized clinical trial. J Arthroplasty 1999;14(02):123-130 
21 Gemmill TJ, Pink J, Renwick A, et al. Hybrid cemented/cementless total hip replacement in dogs: seventy-eight consecutive joint replacements. Vet Surg 2011;40(05):621-630

22 Enoksen CH, Gjerdet NR, Klaksvik J, Arthursson AJ, Schnell-Husby $\mathrm{O}$, Wik TS. Initial stability of an uncemented femoral stem with modular necks. An experimental study in human cadaver femurs. Clin Biomech (Bristol, Avon) 2014;29(03):330-335

23 Koyano G, Jinno T, Koga D, Yamauchi Y, Muneta T, Okawa A. Comparison of bone remodeling between an anatomic short stem and a straight stem in 1-stage bilateral total hip arthroplasty. J Arthroplasty 2017;32(02):594-600

24 Tai CL, Lee MS, Chen WP, et al. Biomechanical comparison of newly designed stemless prosthesis and conventional hip prosthesis-an experimental study. Biomed Mater 2005;18:122-131

25 Liska WD, Doyle ND. Use of an electron beam melting manufactured titanium collared cementless femoral stem to resist subsidence after canine total hip replacement. Vet Surg 2015;44(07): 883-894

26 Manley PA, Vanderby R Jr, Kohles S, Markel MD, Heiner JP. Alterations in femoral strain, micromotion, cortical geometry, cortical porosity, and bony ingrowth in uncemented collared and collarless prostheses in the dog. J Arthroplasty 1995;10(01):63-73

27 Meding JB, Ritter MA, Keating EM, Faris PM. Comparison of collared and collarless femoral components in primary uncemented total hip arthroplasty. J Arthroplasty 1997;12(03):273-280

28 Demey G, Fary C, Lustig S, Neyret P, si Selmi T. Does a collar improve the immediate stability of uncemented femoral hip stems in total hip arthroplasty? A bilateral comparative cadaver study. J Arthroplasty 2011;26(08):1549-1555

29 Bergmann G, Graichen F, Rohlmann A. Hip joint loading during walking and running, measured in two patients. J Biomech 1993; 26(08):969-990

30 Enoksen CH, Gjerdet NR, Klaksvik J, Arthursson AJ, Schnell-Husby O, Wik TS. Deformation pattern and load transfer of an uncemented femoral stem with modular necks. An experimental study in human cadaver femurs. Clin Biomech (Bristol, Avon) 2016; $32: 28-33$

31 Sumner DR. Long-term implant fixation and stress-shielding in total hip replacement. J Biomech 2015;48(05):797-800

32 Ellison B, Cheney NA, Berend KR, Lombardi AV Jr, Mallory TH. Minimal stress shielding with a Mallory-Head titanium femoral stem with proximal porous coating in total hip arthroplasty.J Orthop Surg Res 2009;4:42

33 Piao $\mathrm{C}, \mathrm{Wu} \mathrm{D}$, Luo $\mathrm{M}$, Ma $\mathrm{H}$. Stress shielding effects of two prosthetic groups after total hip joint simulation replacement. J Orthop Surg Res 2014;9:71

34 Maquet N, Simonet J, Marchin N. Etude photoelastique du genou. Rev Chir Orthop Repar Appar Mot 1966;52:3-11

35 Sadowsky SJ, Caputo AA. Effect of anchorage systems and extension base contact on load transfer with mandibular implantretained overdentures. J Prosthet Dent 2000;84(03):327-334

36 Clelland NL, Gilat A, McGlumphy EA, Brantley WA. A photoelastic and strain gauge analysis of angled abutments for an implant system. Int J Oral Maxillofac Implants 1993;8(05):541-548 